\title{
JUGUEM A “GOALBALL” A L’ESCOLA
}

\author{
Gemma Solé Boronat. Professora d'Educació Física al C.P. Cèsar August. Tarragona.
}

\section{Resum}

Amb l'aplicació de l'actual reforma educativa hi ha la possibilitat que en les escoles ordinàries pugui estudiar un nen amb discapacitats. Com que aquesta possibilitat encara no és gaire real, com el cas del meu centre, vaig decidir fer una experiència d'iniciar el goalball, esport practicat únicament per deficients visuals, amb nens normals.

\section{Introducció}

El 3 d'octubre de 1990 es va aprovar la Llei Orgànica d'Ordenació General del Sistema Educatiu, anomenada popularment per les seves sigles: LOGSE.

Amb aquesta nova llei, l'educació en l'Estat espanyol ha conegut un notable impuls deixant enrere algunes mancances del passat. Entre les àrees d'ensenyança on hi ha hagut una millora substancial, cal destacar l'Educació Física.

Un dels punts innovadors de l'actual reforma educativa és l'atenció a la diversitat. Dins d'aquest apartat quedaria inclosa l'atenció singular als alumnes amb necessitats educatives especials, entre els quals es trobarien els alumnes amb discapacitats.

A l'escola ordinària, tradicionalment sempre hi han anat els nens anomenats "normals" a nivell físic, i hi ha hagut una sèrie de centres 0 escoles especials per als nens amb discapacitats. Amb la LOGSE s'obre un nou camí perquè els nens amb alguna deficiència puguin accedir a les escoles ordinàries i puguin seguir una ensenyança individualitzada amb l'aplicació d'adequacions curriculars individuals (ACl) als currículums ordinaris.

Parlar d'activitats físiques adaptades en un centre d'ensenyança ordinari permet de situar-nos en un univers de l'activitat física molt concret i que recull aspectes específics que no descriu l'activitat física normal, en la qual el professorat especialista d'educació física no es troba suficientment preparat.

L'adequació dels currículums als alumnes amb necessitats educatives especials en l'activitat física adaptada és una tasca difícil de realitzar en els centres, tant per la manca de preparació dels professionals involucrats com per la dificultat d'adequar les instal-lacions i els pocs recursos disponibles per a aquest fi.

La reforma educativa suposa que els docents i les noves promocions d'especialistes en educació física estan preparats per atendre els alumnes amb discapacitats.
Però aquest supòsit està força allunyat de la realitat, ja que els professors que ens dediquem a l'ensenyança de l'educació física tenim una formació bàsica molt general i no disposem de recursos suficients per atendre aquest tipus d'alumnes.

En el cas que s'hagués de fer una adequació curricular, caldria una preparació específica que no pot donar la formació general, ja que ens trobem que en els plans d'estudi de tots els centres de formació de mestres de Catalunya, en l'especialitat d'Educació Física, no figura com a assignatura obligatòria ni optativa. Llavors aquestes diferències entre allò que es vol fer i el que es pot fer realment originen problemes per aquest intent d'integrar els nens amb necessitats educatives especials a les escoles ordinàries.

$\mathrm{Si}$ ens apropem a la realitat de les escoles ordinàries, trobem que aquest intent d'integració encara es troba força allunyat de les facilitats que ofereix l'actual reforma educativa. Els nens que van a aquestes escoles no coneixen la realitat d'altre tipus d'alumnes que, per les seves discapacitats, necessiten una atenció individualitzada. Els costa de creure i de pensar, per exemple, que hi ha nens cecs que poden jugar a pilota o nens amb síndrome de Dawn que poden jugar a bàsquet... Aquesta desconeixença fa que per als alumnes normals, els nens amb alguna minusvalidesa no es trobin dintre del seu àmbit de relació.

Em trobava en el cas de ser professora de Primària especialista en educació física, amb la possibilitat de tenir algun nen amb alguna discapacitat. Davant la meva manca de formació específica en aques àmbit, em vaig decidir a fer el postgrau en activitats físiques adaptades. En una de les pràctiques d'esport adaptat vaig anar a veure un entrenament d'alt rendiment de goalball de l'ONCE. Com que em va agradar tant, els vaig dir que em deixessin una pilota per donar a conèixer aquest esport als meus alumnes. L'experiència va ser tan positiva per a ells com per a mi mateixa que l'he volgut donar a conèixer amb aquesta publicació, ja que és una activitat innovadora i molt fàcil de preparar pel poc material que es necessita i per la facilitat de posar-la a la pràctica.

\section{Desenvolupament de l'activitat \\ Material \\ - 1 pilota de goalball. \\ - corda.}




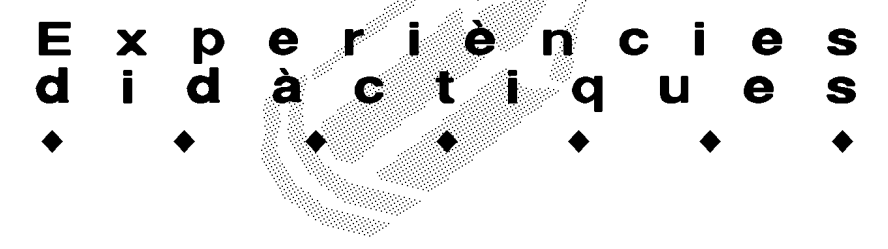

- cinta d'embalar.

- vídeo de presentació dels "Paralímpics de Barcelona 92".

- 1 ulleres de piscina o un mocador per alumne.

\section{Instal-lacions}

Les mesures oficials d'un camp de goalball corresponen a les d'un de voleibol.

Podia aprofitar les línies marcades d'un camp exterior, però vaig preferir dur a terme l'activitat en un recinte interior més petit, exclusivament per a aquest fi.

Gràfic del camp i mesures:

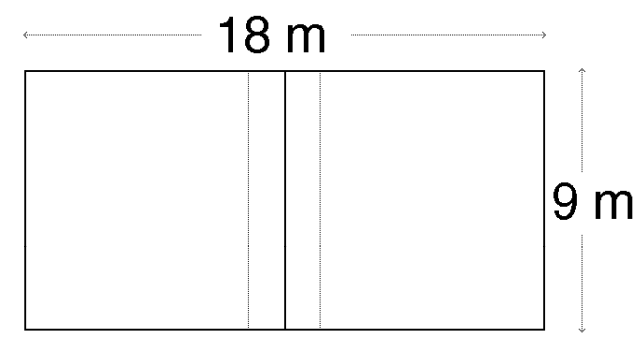

\section{Objectius}

- Conèixer els esports que practiquen la gent amb minusvalidesa.

- Practicar el goalball com a esport per a deficients visuals.

- Desenvolupar altres sentits com el tacte i l'oïda en la pràctica de l'esport.

- Fomentar la cooperació i l'aceptació de la gent amb discapacitats.

\section{Temporització}

L'activitat anava destinada als alumnes de 5 è a 8è d'una escola pública, que tenen dues hores setmanals d'educació física. L'activitat es duria a terme durant una setmana en les dues sessions de classe.

\section{Metodologia}

En la primera hora de classe em vaig ajudar dels sistemes audiovisuals com el vídeo, motivador per si mateix, per introduir el goalball. Després es van explicar les normes que regeixen aquest esport, per passar posterioment a la pràctica. La metodologia utilitzada, tot i que en un primer moment va ser directiva, amb la finalitat de donar a conèixer la normativa de l'esport, va consistir totalment en la resolució de problemes en la seva pràctica.

Els alumnes sortien de 3 en 3 , cada un d'ells amb un acompanyant que tenia com a única finalitat col-locar el jugador en la seva zona del camp.

\section{Desenvolupament de l'activitat}

En el començament de la primera hora de classe van veure el vídeo ( $15 \mathrm{~min}$. aprox.) que va servir perquè els alumnes coneguessin els esports que practiquen la gent amb minusvalidesa. En el moment que es veia el goalball vaig parar la cinta per posar èmfasi en aquest esport que practicarien posteriorment.

Després vam estar fent comentaris, aprofitant que molts d'ells havien vist alguns d'aquests esports en els jocs paralímpics de Barcelona 92. A continuació els vaig donar la següent informació teòrica mínima perquè poguessin jugar correctament al goalball:

- Esport d'equip per a deficients visuals.

- El poden practicar homes i dones en categories diferenciades.

- L'equip està compost de 3 jugadors de camp.

- Les instal-lacions en una competició són el mateix que un camp de volei.

- Gràfic del camp:

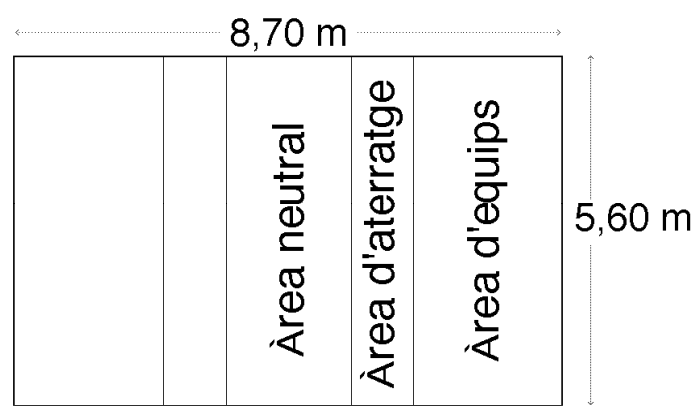

- La pilota pesa 1,25 kg. Té l'esfèrica com una pilota de bàsquet amb 8 forats $i$ a dintre té cascavells.

- El joc consisteix a fer gol a l'equip contrari.

- Tenen l'obligació de portar unes ulleres especials que no els permeten la visió.

- Prohibit que hi hagi sorolls a prop de la sala: bars, trens...

- Durada del partit, 14 min (dues parts de 7 min cadascuna) amb un descans de 3 minuts.

- S'inicia el joc amb una moneda on s'escolleix camp o pilota.

- La pilota ha de tocar almenys un cop l'àrea neutral perquè sigui gol.

- Cada equip té 8 segons a partir del moment que li arriba la pilota fins que la llança.

- Els jugadors han d'estar agenollats a terra menys al moment de llançar-la, que es poden posar dempeus

- Si un jugador es desorienta, és el seu problema.

- És penal quan un jugador es toca les ulleres durant el partit o quan l'entrenador dirigeix en veu alta (encara que hi ha altres casos). 


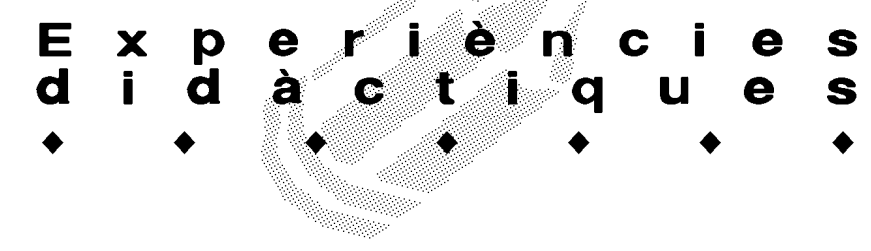

Totes aquestes normes no van ser aplicades estrictament durant els partits. M'interessava molt més que agafessin el joc amb la seva globalitat que el seguiment estricte de la seva normativa.

En la 1a sessió alguns grups-classe van poder començar a practicar aquest esport i va ser realment en la segona sessió on tots els alumnes van poder gaudir de la seva pràctica.

La setmana anterior a l'activitat els havia avisat que portessin unes ulleres de piscina, els alumnes que les tinguessin, que van ser recobertes en el seu interior amb paper d'alumini o amb mocadors de paper; la resta d'alumnes van portar un mocador que igualment va servir per anul-lar-los la visió.

Un cop finalitzada la introducció del tema del món de l'esport en les persones amb minusvalidesa i de l'explicació de les normes bàsiques de l'esport, vam passar a la pràctica. Els alumnes van sortir de 3 en 3 , cada un d'ells amb un acompanyant que tenia com a única finalitat col-locar el jugador en la seva zona de joc.

Com que el camp tenia unes dimensions més petites que un de reglamentari, vaig afegir una sèrie de modificacions:

- Estava prohibit llançar fort la pilota i no estava permès agafar carrera abans de llançar la pilota.

- La durada dels partits tampoc va ser la reglamentària, sinó que anava canviant els alumnes segons el nombre del grup-classe i si hi havien jugat o no en la primera sessió. Una manera fàcil d'anar-los canviant va ser que els que feien d'acompanyants després jugaven i viceversa.

\section{Valoració de l'activitat}

Per al professor ( a nivell personal).

Aquesta activitat va suposar:

- Un treball previ de recollida d'informació d'aquest esport i d'altres practicats per la gent amb minusvalideses.

- Un primer apropament als alumnes per donar a conèixer i fer acceptar el món de les persones discapacitades.

- Trencament de la dinàmica tradicional de les classes d'Educació Física.

- Respecte als mateixos companys de classe que jugaven en situació desavantatjosa en relació al que els és habitual.

- Un treball dels sentits de l'oïda, del tacte i de l'orientació espacial.

Per als alumnes.

- Per a molts va ser el primer cop que sentien alguna informació de gent discapacitada.
- Un apropament per entendre la diversitat d'alumnes que poden estudiar amb ells en l'aplicació de la reforma educativa.

- Els va servir per reflexionar sobre els avantatges que tenen de no patir cap minusvalidesa.

- Van conèixer altres situacions de joc / esport on el sentit de la vista no és determinant per al seu desenvolupament.

- Van haver d'emfasitzar els sentits del tacte i l'oïda per poder jugar correctament al goalball.

- Acostumar-se a treballar sense el sentit de la vista, prioritari en totes les activitats que ells fan.

- Un treball d'equip quan s'anaven passant la pilota entre ells dient prèviament el nom del nen a qui li passaven la pilota.

- Els alumnes que en aquell moment no jugaven ni actuaven d'acompanyants, és a dir, que feien de públic, van haver d'estar amb absolut silenci perquè els alumnes que jugaven poguessin escoltar perfectament el sorroll dels cascavells de la pilota.

\section{Perspectives de l'activitat}

Els alumnes han de començar a ser conscients que amb l'aplicació de la LOGSE poden estudiar amb algun nen que tingui alguna discapacitat. Aquesta activitat va suposar un bon mitjà informatiu dels diferents tipus de minusvalidesa que existeixen.

La valoració d'aquesta activitat que he dut a terme per primer cop amb els meus alumnes l'he considerat molt positiva. De cara al proper curs escolar es podria tornar a repetir, però amb les dimensions del camp reglamentàries. Es podria ampliar també amb la pràctica d'altres esports que practiquen la gent amb minusvalidesa, com podria ser la de voleibol adaptat, la boccia... on no es requereix cap material extraordinari. És a dir, seria molt convenient que de cara al proper curs escolar es fes una unitat de programació amb el títol d'activitats físiques adaptades.

\section{Bibliografia}

Apunts del Curs de Postgrau Activitats Físiques Adaptades. Curs 1995-1996.

Disseny Curricular. Ensenyament Primari. Editat pel Departament d'Ensenyament. Generalitat de Catalunya. BarceIona. 1990.

«Apunts» 38 (1994). Ed. Institut Nacional d'Educació Física de Catalunya. Barcelona.

«Interaula» 24-25 (1995). 